\title{
Toyota Motor Corporation: Organizational Culture
}

\author{
Sergey Sosnovskikh \\ University of Greenwich
}

\begin{abstract}
This paper investigates the organizational culture of one of the largest auto manufacturers in the world Toyota Motor Corporation using various corporate culture and management models. The investigation was conducted in 2009 using qualitative analysis with the help of various secondary sources. The study reveals that the company's management style can be characterized as the Family type that implies collectivistic society with male domination, strict rules and laws at work, and long-term orientation. It is also based on several essential principles, such as continuous improvement and learning, respect for people, mutual trust, and teamwork. Two core elements of the Toyota's success are technological innovations and qualified human resources.
\end{abstract}

Keywords: Toyota Motor Corporation, organizational culture, management model, Japanese culture, Hofstede, kaizen

\section{Introduction}

Since 1937, the Toyota Motor Corporation has become one of the largest auto producers in the world and it is still evolving and penetrating different national markets all over the world. The company is also famous for its high-quality vehicles and innovative technologies (Winfield 1994). How does the company manage to do that? What is the secret?

First of all, in this work, the definition of organizational culture will be given. Secondly, four models of organizational culture will be discussed to comprehend how these models characterise Japanese culture. Thirdly, Toyota's management style will be deeply analysed. After that, it will be rather important to find out if the Toyota management style is the reflection of Japanese culture. Finally, the strategic development of the company will be identified; moreover, Toyota's culture will be evaluated to understand its impact on the strategic development of the company. This study was conducted in 2009 using qualitative analysis with the help of relevant secondary sources, such as books, academic articles, and various reports.

\section{Organizational Culture, Cultural Models}

There are some definitions of organizational culture. Schein $(2004,17)$ states that organizational culture is a structure of common assumptions that are distributed among all members of the group to solve internal and external problems of an organization and to share their knowledge with new members. Organizational culture is directly connected to the system of "shared meaning" (Robbins 1990). Any new member of a department or organization usually faces its different cultural elements such as beliefs, rituals, myths, and practises;

Sergey Sosnovskikh, M.Sc. International Management, Ph.D. student, International Business and Economics Department, University of Greenwich, UK; main research fields: Industrial Clusters, Special Economic Zones, International Management, Business, Economics, International Trade and Markets, and International Relations. 
accordingly, all these elements help the members of an organization easily understand each other at work and know how they should behave (Robbins 1990). Figure 1 shows how culture evolves inside the organization.

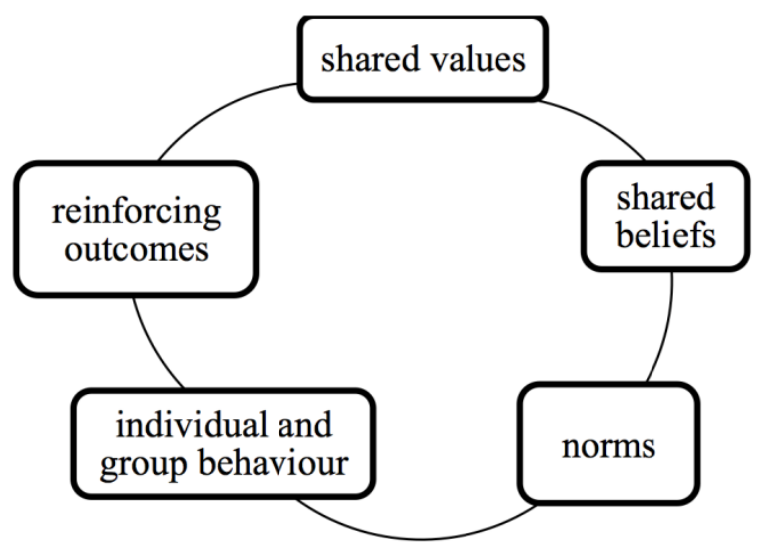

Fig. 1. The stages of cultural formation (Source: Boddy 2008, 86).

First of all, people try to develop and share their common values to define beliefs and norms that can help them comprehend the way they should communicate with each other separately or as a team. Secondly, as a rule, positive outcomes reinforce these norms and beliefs, which consequently enhance confidence in common understanding inside the company. It is important to know that if people in an organization work with these issues more and more, it may lead to better performance (Boddy 2008).

In culture, there are some particular dimensions or characteristics that are closely connected with each other. Robbins (1990) suggests ten features, which contain both behavioural and structural dimensions.

(1) Individual initiative: this characteristic describes responsibility, freedom, and independence that individuals have;

(2) Risk tolerance: it shows if employees have an ability to risk or to innovate in crucial situations;

(3) Direction: it speaks about organization's objectives and plans;

(4) Communication patterns: it defines the level to which the formal hierarchy of authority confines organizational communications;

(5) Reward system: employees can be awarded for the performance;

(6) Control: to a certain extent, employees' behaviour must be regulated by some rules;

(7) Integration: different departments in an organization are recommended to work in cooperation;

(8) Conflict tolerance: employees can speak about their problems and explain their disagreements frankly;

(9) Management support: managers should give their employees any support for better performance and results;

(10) Identity: this characteristic describes that members express their solidarity with the whole organization rather than only with their team.

Schein proposes three levels of culture that look like a pyramid or an iceberg as people see the surface of it when the important aspects of culture are hidden deeper. Figure 2 shows these three levels of the pyramid (Schein 1984; Liker and Hoseus 2008).

(1) Artefacts and behaviour are those elements that can be seen at the surface level. At this level, we notice dress, a layout of the workplace, people's behaviour, logos, etc. These observations are useful but do not disclose the full essence. 
(2) Norms and values. Norms are rules of behaviour that are accepted by every member of the company; even if these rules are not written down, everybody knows them: basic rules of behaviour, how to dress, if it is acceptable to be late, what is appropriate to say, how to speak with the boss and many others. Values are principles we live by. Overall, this level talks about the philosophy of the company, norms, rules, values, and principles.

(3) Underlying assumptions. This level is about what people deeply believe, how they act subconsciously, beliefs that are taken for granted about their organization and work, about other people that surround them, rewards and punishments.

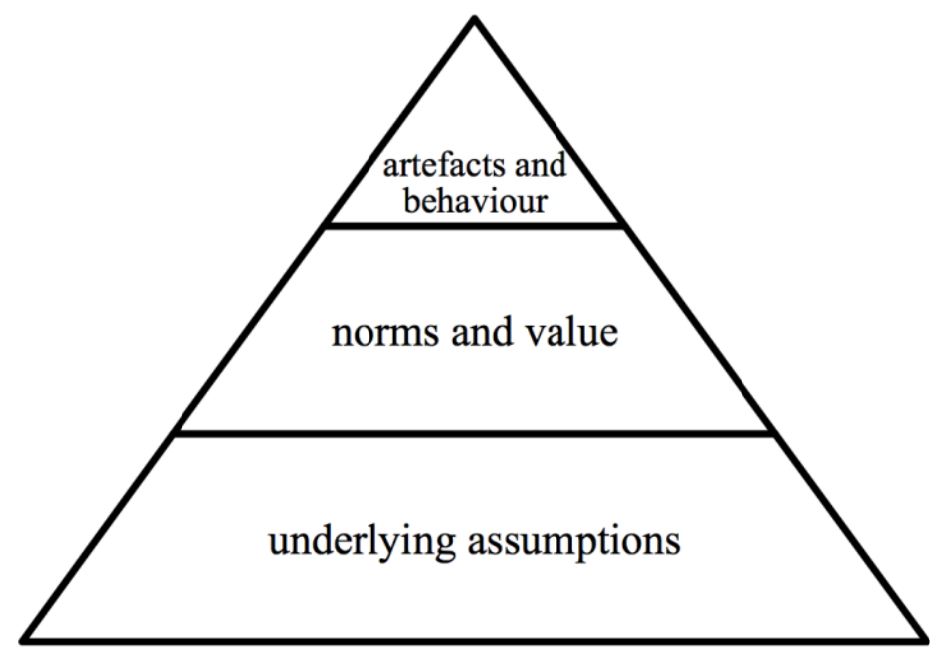

Fig. 2. There levels of culture (Source: Schein 1984 in Liker and Hoseus 2008, 6).

According to Charles Handy, there are four types of organizational culture (Boddy 2008, 89-90).

(1) Power culture: when a dominant central figure with the help of his or her power influences other people in an organization;

(2) Role culture: when managers give clear job requirements, where everything is explained in detail so that people are employed only when their skills correspond to these requirements;

(3) Task culture: individuals work in teams in order to unite their skills to complete their task or project;

(4) Person culture: in this culture, there is an individual in the center of attention where everybody in an organization works for this individual's needs.

Culture in an organization is directly connected with the employee performance and with the efficiency of the company because it has an essential impact on how to take the decisions, how to use human resources, and how the company should solve environmental problems (Trompenaars and Woolliams 2004). Trompenaars and Woolliams (2004) outline three aspects of organizational relationships:

(1) Common relationships among employees in the organization;

(2) The vertical and hierarchical relationships that usually exist between employees and their subordinates or superiors;

(3) Relationships of the employees in the company overall.

On Figure 3, Trompenaars and Woolliams (2004) suggest four types of organizational culture, which are based on two dimensions: Hierarchical or Egalitarian and Task or Person. Incubator culture type implies a low 
level of formalisation and centralization distinguishes people-oriented culture. The organization works to satisfy the needs of its employees. Moreover, all tasks and responsibilities are given to the members of the company on the basis of their preferences and requirements. The structure of this company is usually adaptable. Overall, the main features of this type of culture are the power of individual, self-realization, professional approval, and adherence to oneself.

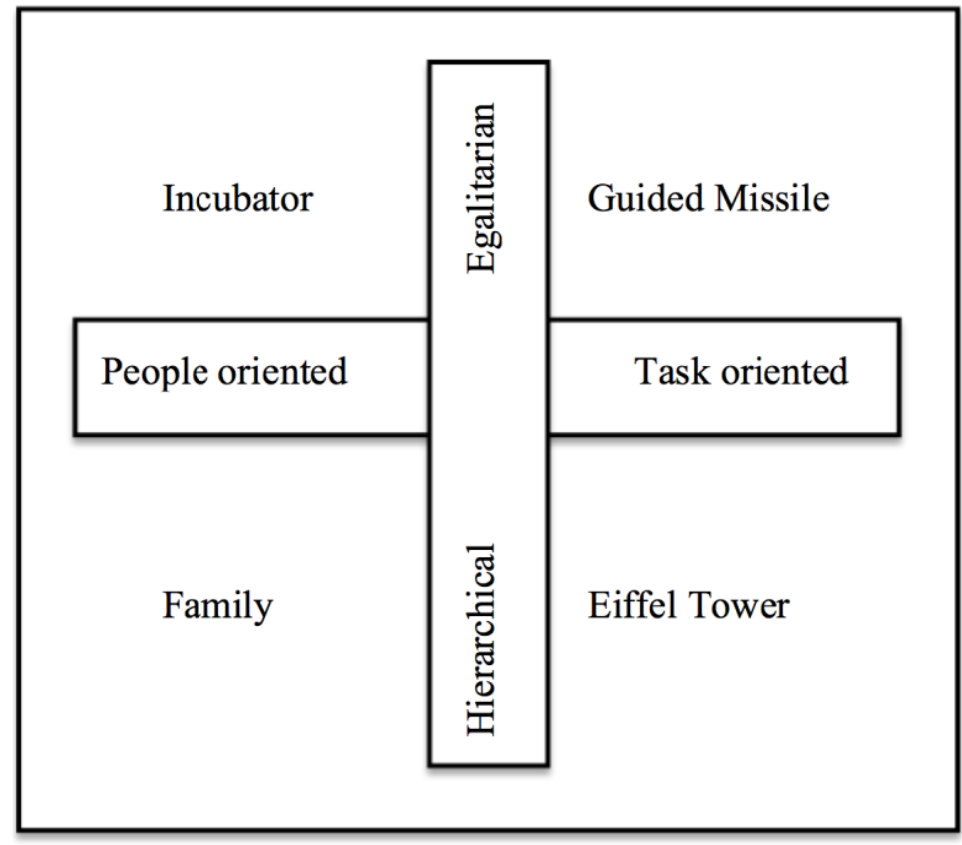

Fig. 3. Four types of organizational culture (Source: Trompenaars and Woolliams 2004, 106).

Family type involves a high level of centralization and a low level of formalization. It is a highly personalized organization, where its members work around the central power-an absolute leader who generally guides the company and controls it. However, employees try to be closer to that centre as it is the source of power. Despite the fact that the climate inside the company is rather manipulative, there is not so much bureaucracy or rules. Everything is based on personal relationships and trust. Guided Missile means a low level of centralization and a high level of formalization. In this culture, everything is directed to complete the task or the project. Organizational relationships are oriented to the results, where every member of the team has its task on the basis of his or her skills. Everything in this culture is conducted by the goal of the company. Efficiency and achievements of an organization are assessed higher than authority and responsibilities because they may be amended due to the changes in the type of work. The main manager is a team leader, who has complete control. But at the same time, in this culture, it is rather difficult to manage the team because of the absence of centralization in management. This task-oriented management style is really efficient in quick response to urgent changes. That is why this type of culture mainly implies project and matrix forms of organizations. Eiffel Tower culture type implicates high level of formalization and a high level of centralization. Control is based on precise rules, juridical procedures, established rights and responsibilities. Also, this type of culture implies bureaucracy, which makes the organization unalterable. Employees are usually punctilious and accurate; in addition, they appreciate order and predictability. The authority acquires its status on a basis of 
skills and functional position; therefore, the authority acquires respect. In this type of culture, members of the organization see their work as a duty, but not as an obligation; furthermore, that significant factor leads to better performance. Eiffel Tower culture type is rather burdensome if any changes are going to occur. This type of organization is sluggish to adapt.

According to Trompenaars and Hampden-Turner (1997), Japanese culture can be characterized as the Family culture type. In major Japanese organizations, some warm relationships exist between employees of different ranks, which imply leniency to younger people and respect for the older. Therefore, there is a concept that Japanese employees tend to do more than they are obliged to do at work. Promotion throughout the company is determined by age; consequently, the oldest acquire more responsibilities. Finally, this devotion to the organization becomes long-term, as members of this organization are faithful to it (Trompenaars and Hampden-Turner 1997).

Hofstede and Hofstede (2004) define the organizational culture in the way by saying that culture is some aggregate programming of people's mind that has a significant impact on how they react to various occurrences and outcomes in their workplaces. They have done research about national cultural differences and created a model that identifies five fundamental dimensions of culture (Hofstede and Hofstede 2004).

- Power distance: this dimension focuses on the question of equality and inequality in the company. A high level of this index means that people accept an inequality in power and wealth, a low level means they do not accept it;

- Individualism and collectivism: focuses on to what extent individuals are integrated into groups. In individualistic societies, people look after themselves; in collectivistic societies, people belong to the strong cohesive groups and they are usually responsible for their fellow members and for what they do as a group;

- Masculinity and Femininity: this index focuses on gender discrimination. A high level of this index means male domination in society. Low level of the index means that society has a low level of gender differentiation and discrimination; in these countries, women are treated equally to men in all aspects.

- Uncertainty and avoidance: this index focuses on society's tolerance for ambiguity and uncertainty. A high level of this index means that this society prefers accurate rules, laws, control, and other various regulations to reduce the uncertainty; a low level of the index means that society is less anxious about uncertainty and more tolerable for different changes, options and it tends to take various risks.

- Time Orientation: a high level of this index means that society tends to be more long-term thinking; a low level of this index means that society tends to be more short-term thinking where changes may occur more quickly.

On Figure 4, Hofstede suggests the analysis of Japanese culture on the basis of five dimensions (Itim International 2009). So, Japanese culture can be characterized in the following way:

- People accept inequality in power and wealth to a certain extent;

- Collectivistic society;

- Male domination;

- Precise structure of standardized work, strict rules, laws, control, and other different regulations;

- Long-term orientation. 


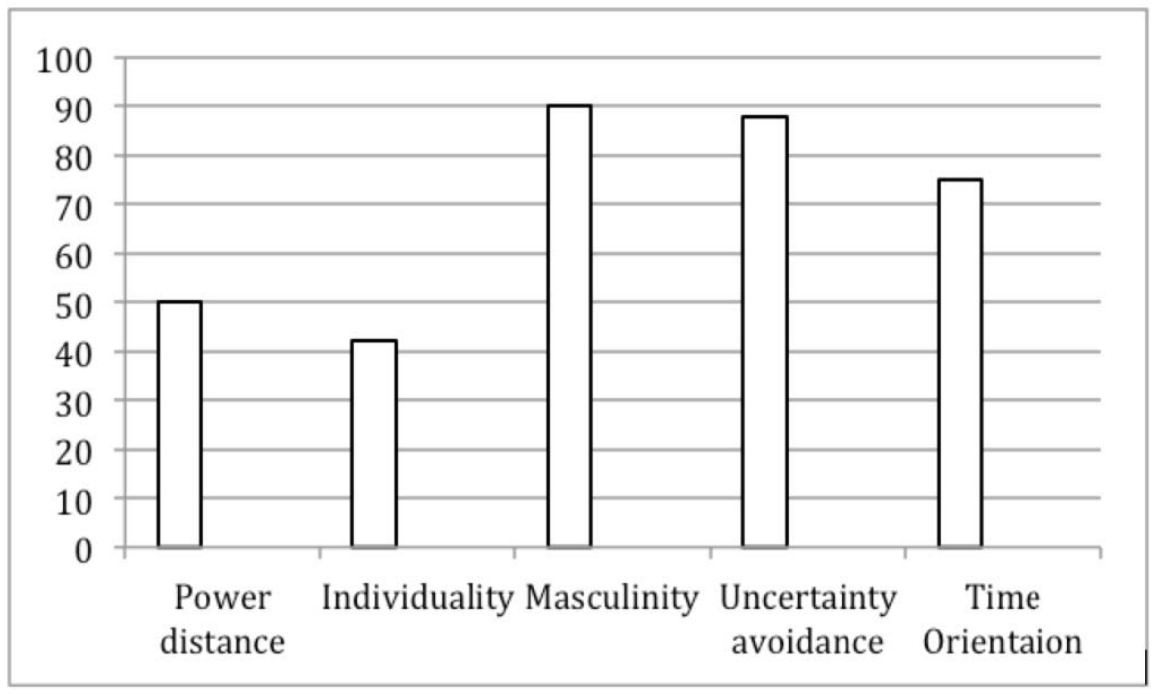

Fig. 4. Hofstede's analysis of Japanese culture (Source: Itim International 2009).

It can be explained, as organizations in Japan tend to mix two cultural values: collectivistic feature, which came from rice culture and the "spirit of service of the Samurai" (Morgan 2006, 118). Rice growing activity used to be insecure because of a shortage of land and too short of seasons that are pleasant for growing it. That is why the growing process implied working in a team to achieve best results. Everyone should do their best to assure that general outcome of work corresponds the expected quality. If an individual or a family makes a mistake, the whole system is damaged; therefore, the entire group is punished. Nobody is a winner or a loser, because everybody in community respects each other, as everybody is dependent on each other; finally, rice culture was gradually transmitted to the Japanese enterprises and factories (Morgan 2006).

The "service of the samurai" appeared when there were people who looked after rice farmers. It played an essential role in bureaucratic and military systems of Japan, which now can be compared to managerial clans that rule the Japanese society. This kind of relationships between organizations and society can be especially noticed in collaboration between banks and Japanese industries; for instance, banks give necessary support to business when it is really needed. Hierarchy in a Japanese organizational culture contains not only top-down control but, also, it focuses on mutual service. As the whole culture is penetrated with the "spirit of samurai," in a Japanese organization workers can deserve self-respect not by competing against the system of service, but working within it. Therefore, employees always try to improve the efficiency of their company by coming early to their workplace and leaving it late (Morgan 2006).

\section{Toyota Motor Corporation}

\subsection{Background}

Toyota Motor Company was founded in 1937. In 1950, Toyota Motor Sales was established and in 1982, they merged into Toyota Motor Corporation. Two years later, the company entered a joint venture with General Motors (NUMMI - the New United Motor Manufacturing Inc.), after that they started production of vehicles in the USA and in 1989 the new brand "Lexus" was launched. In 1992, Toyota began its production in the UK; moreover, in the beginning of 1990s, the company launched a large variety of new vehicles to its line-ups, such as compact and luxurious cars, various types of sport cars, SUVs, and huge pick-ups for the American market; 
finally, in 1997, it started the production of the currently best-selling hybrid car known as the "Prius." In 2002, Toyota entered the famous Auto World Championship "Formula One" (Toyota Motor Corporation, 2009).

Toyota's core products and services are as follows:

- Auto manufacturing: the company is developing its technologies in producing comfortable and safe vehicles;

- Environmental technologies: Toyota is anxious about environmental pollution; therefore, it creates hybrid cars with new engines, new types of fuel, and new recycling technologies;

- ITS: an invention of road traffic systems;

- Personal Mobility Vehicles: absolutely new types of vehicles with new technologies;

- Robot Technologies: production of various robots under the concept of "harmony with people;"

- Toyota Financial Services: the company provides different financial services such as crediting, leasing, insurance, etc.

The headquarters of the company are located in Toyota City, Nagoya of Aichi Prefecture and Tokyo, Japan. By 2009, Toyota has established manufacturing plants in 28 countries all over the world: Japan, Canada, USA, Argentina, Brazil, Columbia, Mexico, Venezuela, Czech Republic, France, Poland, Portugal, Turkey, UK, Russia, Kenya, South Africa, China, Taiwan, India, Indonesia, Malaysia, Pakistan, Philippines, Thailand, Vietnam, Australia, and Bangladesh (Toyota Motor Corporation, 2009).

At the end of March 2009, the capital of Toyota Motor Corporation was 395.05 billion yen (Toyota Motor Corporation, 2009). According to Forbes (2009), Toyota was the third leading company in the world in August 2009; however, in January 2009, the company suffered from the crisis and its production level fell by almost 40 percent (McCurry 2009). In the first half of 2009, net revenues of Toyota Motor Corporation fell by 31.3 percent in comparison with the similar fiscal period of the previous year; operating income dropped by 137 billion yen, net income declined by 56 billion yen; nevertheless, in the financial services, segment operating income increased by 17.2 billion yen comprising 16.9 billion yen of valuation gains on interest rate swaps (FY2010 2Q Financial Results 05/11/2009 in Toyota Motor Corporation, 2009).

\subsection{Toyota Organizational Culture}

Two models can characterize Toyota culture. One of them was presented in internal training document “The Toyota Way 2001," which was published for employees to introduce their main features and values of the management style of the company (Hoseus and Liker 2008). On Figure 5, the model is depicted as a house, where the culture of the company stands on two pillars: Continuous Improvement and Respect for People. Continuous Improvement has three sub-categories that are shown as the foundation of the house (Hoseus and Liker 2008).

- Challenge: long-term thinking, encountering various problems and risks, making up new ideas, and looking for solutions;

- Kaizen: permanent evolution, making innovations, continuous improvement of all aspects of the company;

- Genchi genbitsu: seeking for ways to make right decisions, agreements and doing your best to achieve organization's purposes. 


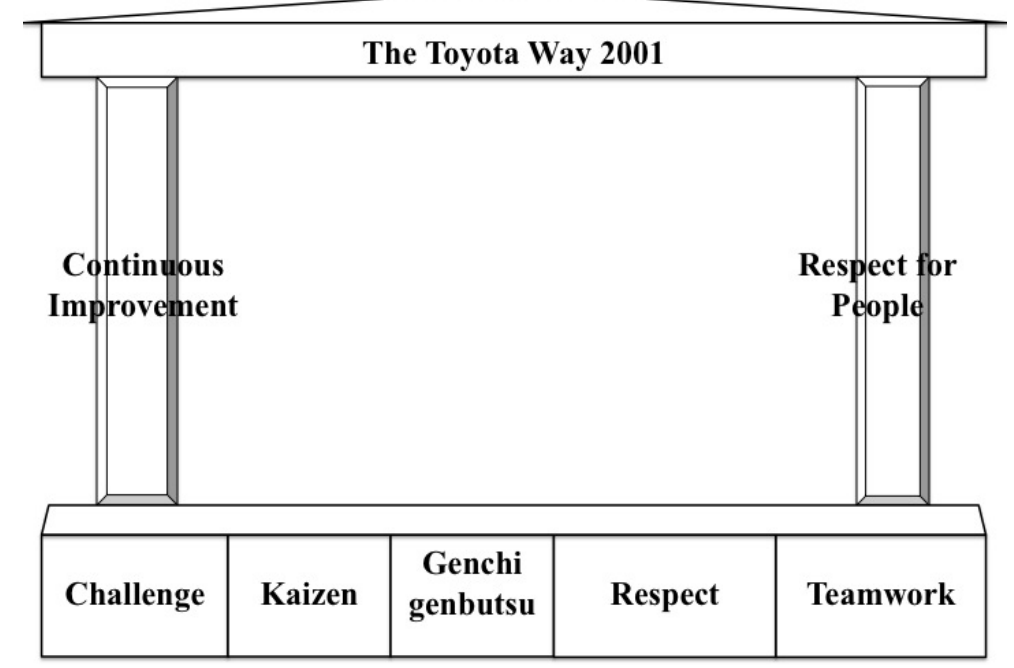

Fig. 5. The Toyota Way 2001 (Source: Hoseus and Liker 2008, 40).

The second pillar is Respect for People that stands on the foundation where there are two sub-categories:

- Respect: respect all people who surround you, try to avoid any misunderstandings, accept responsibilities and form mutual trust;

- Teamwork: motivate personal and professional improvement and development, work as a team.

Liker (2003) suggested 4P model, which is depicted on Figure 6 as a pyramid with four levels:

- Philosophy: the foundation of the pyramid is a long-thinking philosophy that concentrates on exceeding the needs and expectations of the buyers;

- Process: based on the fact that Toyota's investments are directed in research and development sphere, the company can create more efficient processes;

- People and partners: efficiency is made by people who operate the company, where company's culture teaches people to work together in a team for common purposes;

- Problem-solving: employees always look for ways to solve various problems of the company, which implies constant self-improvement and learning.

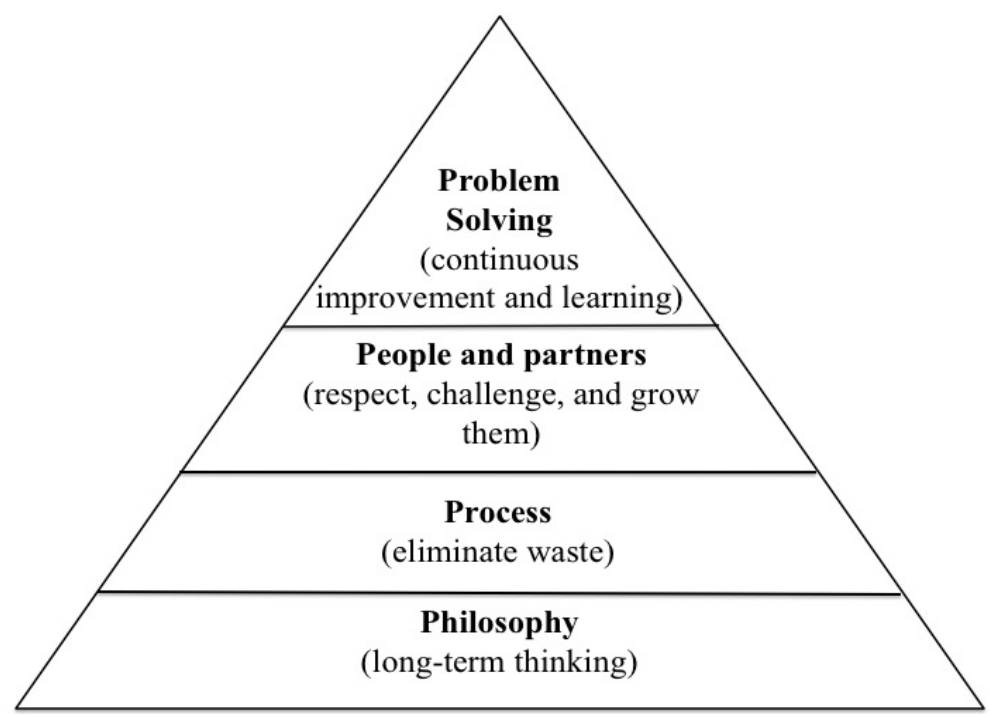

Fig. 6. 4P model of the Toyota Way (Source: Liker 2003, 13). 
In both models, all their elements are closely connected to each other, and every element is important; therefore, if any of them is missed, the entire system suffers. Both models emphasize that continuous improvement and respect for people are essential elements in organizational culture. The employees should clearly comprehend the value of the process and results: they are not praised for the project till they have precise necessary results, which relate to the objectives of the company; moreover, employees should follow the right structure of the process and should realize what they have learnt from doing this project. Teamwork is a fundamental element in Toyota organization, and Toyota claims that the perfect number of employees in a team is five (Figure 7) because it is easier to control; furthermore, these small teams are more capable of solving problems and maintaining mutual trust. To do this, there are three significant items that Toyota follows (Hoseus and Liker 2008, 235):

- The use of matrix style of management;

- Distribution of decision-making policy is based on exact standards;

- Clear identification of the team leader's functions.

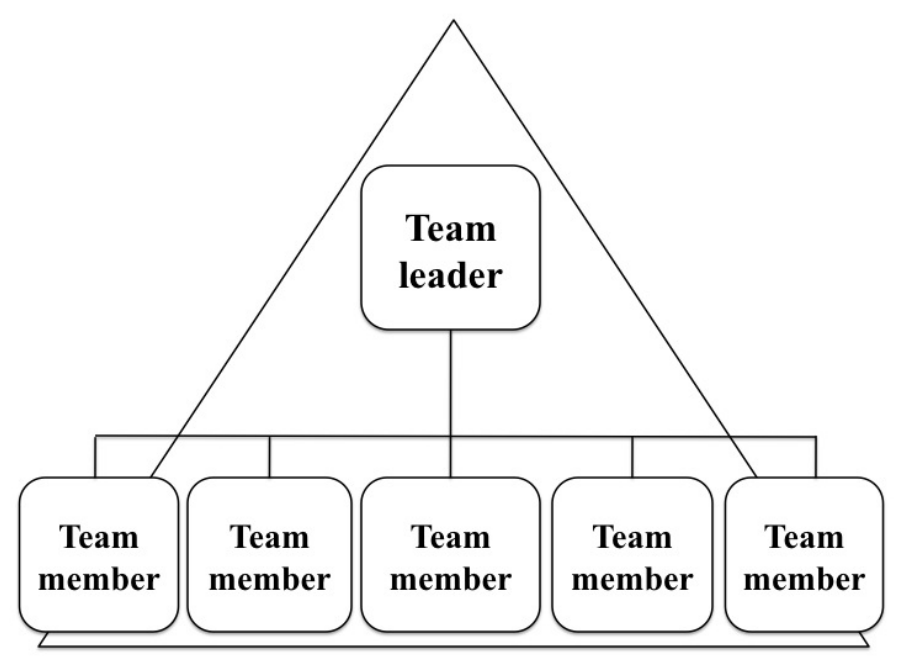

Fig. 7. The structure of a small team in Toyota organization (Source: Hoseus and Liker 2008, 233).

Every small team has a team leader, who is responsible for control, supervising and examining the process of work and its results, assuring safety and solving problems; moreover, this team leader teaches new employees all aspects of Toyota culture. As members of the group are supposed to improve themselves, a team leader is also responsible for the results of their self-improvement (Liker 2003). The company's prosperity depends on the mutual trust that exists within the company between the employers and employees. Employees are concerned about their paychecks, personal growth, excellent benefits, a safe workplace and having a meaningful work; when the company's goals are financial profit, long-term success, quality, contribution to society and quality. Toyota managed to achieve mutual trust (Figure 8), because it is based on mutual long-term prosperity and persistent improvement, as employees do their best to achieve company's objectives; after that, the company compensates what they deserve (Hoseus and Liker 2008). 


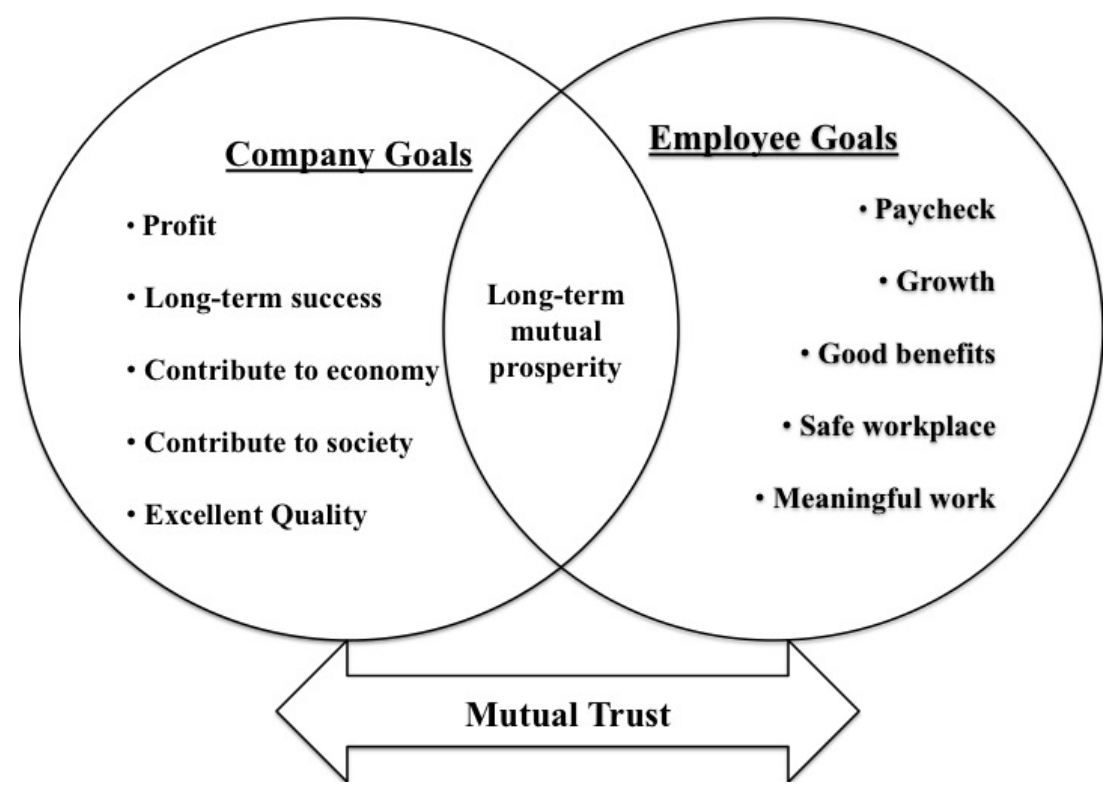

Fig. 8. Mutual Trust between the company and employees (Source: Hoseus and Liker 2008, 52).

Also, Toyota tries to minimize social discrimination between the employees and managers; that is why everyone has the same uniform, there are no executive parking areas, no executive dining rooms and even offices - all members have equal favors (Fang and Kleiner 2003, 116-22). Moreover, Toyota wants its people to be devoted to the company and motivated by what they learn and do at work. There is a particular process of development of this devotion in Toyota culture: For instance, an individual is employed, learns the job and understands how it must be done, evolves to a level of dedication, moves to a better position within the company and learns it again, gains experience and skills; finally, this process inspires the person to work and to be dedicated to the company deeper and deeper (Hoseus and Liker 2008).

Mutual trust is also an essential component in problem-solving process. In different departments of the company, various kinds of subcultures exist; therefore, Toyota has been developing a common culture for all its departments. From time to time, managers are assigned to work in different areas of the organization; by doing that, they are expected to comprehend the essence of work of other departments, analyze its culture, and develop together with team members. In Toyota culture, the significance of problem solving is based on the connection between people and the product value streams (Figure 9); furthermore, it is not only important to have people who are well trained and competent enough to identify and solve problems, but also to have people who can work as a team, to trust their team leader and other members of the team. Finally, the whole system stands on the foundation that contains four essential components: accuracy and punctuality in delivery, stabilization in work, visualization, and standardization (Hoseus and Liker 2008). 


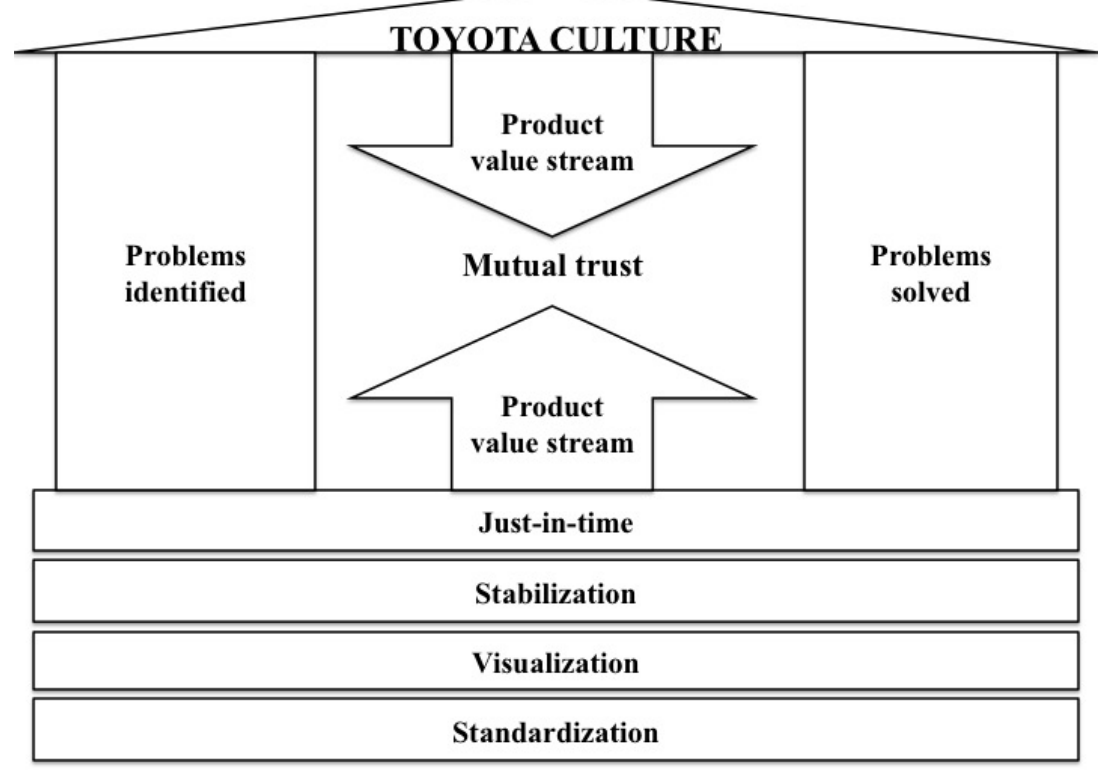

Fig. 9. Problem solving process (Source: Hoseus and Liker 2008, 40).

\section{Strategic Development of Toyota Motor Corporation}

Hoseus and Liker (2008) state that Toyota culture is a reflection of Japanese culture, but it is also unique, as Toyota has a specific approach to managing the company. For instance, when after the Second World War most Japanese companies were copying American systems of mass production, Toyota was trying to create its unique production system that could perfectly suit Japan; furthermore, Japan is a country with almost no natural resources (Winfield and Kerrin 1994). Trompenaars and Hampden-Turner (1997) characterize Japanese culture as the Family culture type, where there are some warm relationships between managers and employees, where a manager is a team leader and a teacher. Hofstede (Itim International 2009) states that Japanese culture is a collectivistic society with male domination, strict rules and laws at work, and long-term orientation. All these elements are essential parts of Toyota management style that make the Toyota Company unique and successful on the international markets (Winfield and Kerrin 1994).

When Toyota establishes a subsidiary in a new country, the company conducts a deep research about national needs, environmental requirements and seeks for the best ways to implement Toyota culture (Hoseus and Liker 2008). Toyota follows the policy "right cars for the right markets" (Direction, 2008). As an example, the company has invented hybrid cars for customers, who care about the environment, and full-size pickups such as the "Tundra" or the "Highlander" specially designed for the American car market, where large cars are in high demand (Direction, 2007). Toyota's strategy is directed on penetrating various international markets and on cutting costs without sacrificing the quality of its products; therefore, the company is developing its different advanced technologies and innovatory processes to produce high-quality cars at lower costs (Direction, 2008). Furthermore, those of Toyota's cultural principles that have been mentioned before (see Part 3.2) also benefit the strategic development of the company (Direction, 2008): Continuous Improvement, Long-term orientation, Teamwork, Mutual Trust, etc.

Besides, when Toyota sets up a new assembly plant in a certain country, the company implements its culture with all its aspects and principles (Hoseus and Liker 2008); especially, the company wants its 
subsidiaries to work in strict conformity with the principles of lean production and quality standards. To achieve that, Toyota sends kaizen instructors to the subsidiary companies to teach local managers and employees Toyota's culture, to transfer technologies, skills and to exchange experiences, as one of the company's principles is the continuous improvement and learning (Elsey and Fujiwara 2000). Elsey and Fujiwara (2000) conducted a survey among kaizen and technology transfer workers from 12 assembly plants, and its results showed that:

- In Toyota and its subsidiaries, most people had worked for more than 10 years and that fact proves the effectiveness of inspiring commitment of the employees to the enterprise, to a certain extent;

- There were only a few women who worked in the computer-assistant design department;

- The majority of respondents belonged to the age group from 30 to 50 , and only about 15 percent were over 50; moreover, age reflected their work position. It means that age and experience go together and depend on work status; for instance, line workers were in the age group of 18 and more;

- The majority of people were proud of the quality of work they were doing and they enjoyed working in the Toyota Corporation.

There is another way how Toyota manages to reduce costs: the company retains its workers who are beyond their retirement age and offers them new jobs overseas. As these managers or employees have a tremendous experience in work in the Toyota Company, they are very useful in teaching and training new employees or non-Japanese employees overseas. Moreover, that also motivates the employees to work in the company in the long run and to be devoted to it (Direction, 2008). Also, Toyota concentrates a lot on technological innovations and on refining its production system. As a result, these two most important factors have become the competitive strategy of the company and now it produces high quality and reliable vehicles at low costs (Elsey and Fujiwara 2000). Finally, the basis of Toyota's success is a perfect production system that leads to cost reduction and the production of quality vehicles (Direction, 2008). Furthermore, the company has two significant forces that help it to evolve: technological innovation and kaizen human resources (Elsey and Fujiwara 2000).

\section{Conclusion}

The foundation of Toyota's principles of management is based on the three levels of culture of Shein's pyramid: artefacts and behavior, norms and values, and underlying assumptions (Hoseus and Liker 2008). Trompenaars and Hampden-Turner (1997) characterize Japanese culture as the Family culture type and Hofstede (Itim International 2009) states that Japanese culture is a collectivistic society with male domination, strict rules and laws at work, and long-term orientation; moreover, Toyota culture is a perfect reflection of Japanese culture (Hoseus and Liker 2008). Toyota's way is based on (Elsey and Fujiwara 2000): continuous improvement and learning, respect for people and mutual trust, teamwork and long-term thinking. These principles help the strategic development of the company, which is penetrating various international markets and the production of quality vehicles at low costs (Direction, 2008). Most people have worked for more than 10 years in the company, and they like what they do, and they are proud of what they do. Finally, there are two main factors that lead the Toyota Company to success: technological innovations and qualified human resources (Elsey and Fujiwara 2000). 


\section{Works Cited}

Boddy, David. Management: An Introduction. Essex: Pearson Education, 2008.

Direction, Strategic. "Driving Ahead: The Great Toyota PR Machine." Strategic Direction 23, No. 10.

Direction, Strategic. "Quality Counts: The Toyota Blueprint for Improvement and Growth.” Strategic Direction 24, No. 4.

Elsey, Barry and Asahi Fujiwara. "Kaizen and Technology Transfer Instructors as Work-Based Learning Facilitators in Overseas Transplants: A Case Study.” Journal of Workplace Learning 12. 8 (2000): 333-42.

Fang, Samsong and Brian H. Kleiner. "Excellence at Toyota Motor Manufacturing in the United States." Management Research News 26. 2/3/4 (2003): 116-22.

Forbes. "The Global 2000." <http://www.forbes.com/lists/2009/18/global-09_The-Global-2000_Rank.html>. 25/12/2009.

Hofstede, Geert and Gert Jan Hofstede. Cultures and Organizations: Software for the Mind: Software for the Mind. New York, London: Mcgraw-hill, 2004.

Hoseus, M. and J. K. Liker. “Toyota Culture: The Heart and Soul of the Toyota Way.” New York: Print Matters Inc., 2008.

Itim, International. Itim International: Geert Hofstede Cultural Dimensions (Japan). $<\mathrm{http}$ ://www.geert-hofstede.com/hofstede_japan.shtml>. 12/12/2009.

Justin, McCurry. "Japanese Carmakers Slash Production by up to $50 \%$." The Guardian Online. $<$ http://www.guardian.co.uk/business/2009/feb/25/japan-carmakers-slash-production>. 25/02/2009.

Liker, Jeffrey. The Toyota Way: 14 Management Principles from the World's Greatest Manufacturer: 14 Management Principles from the World's Greatest Manufacturer. New York: McGraw Hill Professional, 2003.

Morgan, Gareth. Images of Organization. London: SAGE Publications, 2006.

Robbins, Stephen P. “Organization Theory: Structure.” Design, and Applications. San Diego: Prentice-Hall International Inc., 1990.

Schein, Edgar H. Organizational Culture and Leadership. San Francisco: John Wiley \& Sons, 2006.

Toyota Motor Corporation. FY20102Q Financial Results. <http://www.toyota.co.jp/en/ir/financial_results/2010/index.html>. 25/12/2009.

Toyota Motor Corporation. <http://www.toyota.co.jp/en/index.html>. 25/12/2009.

Trompenaars, Fons and Charles Hampden-Turner. Riding the Waves of Culture: Understanding Cultural Diversity in Business. 2nd Edition. London: Nicholas Brealey, 1997.

Trompenaars, Fons and Peter Woolliams. Business across Cultures. West Sussex: John Wiley \& Sons, 2004.

Winfield, Ian. “Toyota UK Ltd.: Model HRM Practices?” Employee Relations 16. 1 (1994): 41-53.

Winfield, Ian and Maire Kerrin. "Toyota and Management Change in the East Midlands.” Journal of Managerial Psychology 9. 1 (1994): 3-6. 